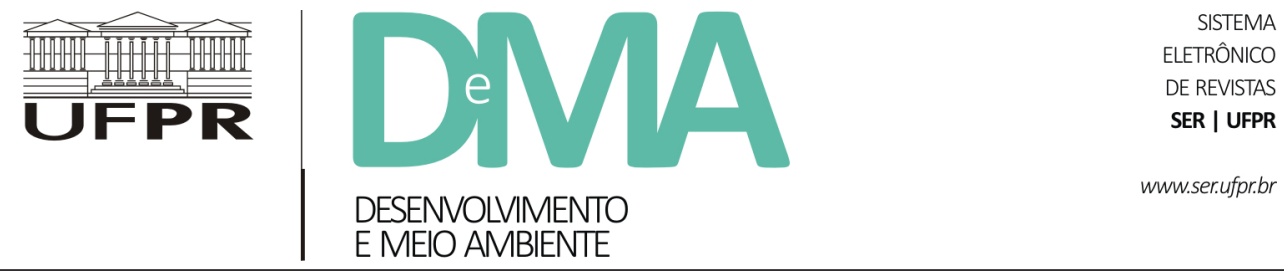

\title{
RESEX Marinha Gurupi-Piriá e políticas públicas educacionais
}

\section{Gurupi-Piriá Marine Extractive Reserve and Public Educational Policies}

\author{
Adria Macedo SANTOS ${ }^{1 *}$, Ligia Terezinha Lopes SIMONIAN ${ }^{1}$ \\ ${ }^{1}$ Programa de Pós-Graduação em Desenvolvimento Sustentável do Trópico Úmido, Núcleo de Altos Estudos Amazônicos (NAEA), Universi- \\ dade Federal do Pará (UFPA), Belém, PA, Brasil.
}

*E-mail de contato: adria.macedo@yahoo.com.br

Artigo recebido em 6 de junho de 2016, versão final aceita em 17 de outubro de 2017.

RESUMO: Neste artigo, discutem-se as políticas públicas educacionais desenvolvidas nos povoados da Reserva Extrativista (RESEX) Marinha Gurupi-Piriá, unidade de conservação (UC) de uso sustentável localizada no município de Viseu, no nordeste paraense. Criou-se essa RESEX pelo Decreto Presidencial de 20 de maio de 2005. Com base na metodologia qualitativa e por meio do estudo dos órgãos governamentais de ensino e instituições representativas, analisam-se as práticas de ensino/aprendizagem em seus diversos níveis e modalidades. Ainda nessa perspectiva, discute-se a condição de envolvimento dos seus usuários nos processos de formulação, implementação e avaliação de políticas públicas educacionais dirigidas a esta UC e, notadamente, de pescadores artesanais, marisqueiras e caranguejeiros. No que concerne aos resultados do estudo, detectou-se a ausência de uma política educacional de qualidade e que reconheça as especificidades do modo de vida das populações tradicionais locais.

Palavras-chave: políticas públicas educacionais; gestão; desenvolvimento sustentável.

ABSTRACT: In this paper it is discussed the public educational policies developed in the villages of the Gurupi-Piriá Marine Extractive Reserve (Reserva Extrativista Marinha de Gurupi-Piriá - RESEX) , a sustainable conservation unit (Unidade de Conservação - UC) located in the Viseu municipality, in the Northeast of Pará. This RESEX was created by a presidential decree in May 20, 2005. Based on a qualitative methodology and in the study of government education agencies and institutes, teaching and learning practices were analyzed in diverse levels and modalities. Still in this perspective, the involvement of its users in the processes of formulation, implementation and assessment of the public educational policies directed to this conservation unit and, notedly, of artisanal fishermen, shellfish gatherers and crab gatherers is discussed. Regarding the results of this study, it was observed that there is no quality educational policy that recognizes the specificities of the way of life of the local traditional populations.

Keywords: public educational policies; management; sustainable development. 


\section{Introdução}

Com o intuito de promover a conservação do ecossistema marinho e contribuir para a valorização e difusão do modo de vida de populações tradicionais pesqueiras, foi criada, em 1992, no litoral de Santa Catarina, a primeira reserva extrativista marinha do Brasil, a RESEX Marinha do Pirajubaé. A partir de 1997, mediante demandas socioambientais, foram criadas nas regiões Nordeste e Sudeste do país mais cinco unidades - RESEX Marinha do Arraial do Cabo, RESEX Marinha Baía do Iguape, RESEX Marinha do Corumbau, RESEX Marinha do Delta do Parnaíba e RESEX Marinha Lagoa do Jequiá.

Notadamente, com a intensificação da demanda advinda de pescadores artesanais em várias partes da costa brasileira, esse número cresceu, sendo atualmente o estado do Pará o que reúne o maior número de RESEX em área costeira e marinha em território nacional. São elas: Marinha de Soure, Chocoaré-Mato Grosso, Maracanã, a Mãe Grande de Curuçá, São João da Ponta, Marinha de AraíPeroba, Marinha de Caeté-Taperaçu, Marinha de Gurupi-Piriá, Marinha de Tracuateua, Marinha Mocapajuba, Marinha Mestre Lucindo e a Marinha Cuinarana. Formaram-se, assim, um cinturão de mangue enorme em área protegida (AP), o maior do mundo, e o conjunto de populações tradicionais pesqueiras mais amplo com outorga da área.

Entretanto, sua efetivação requer a implementação de políticas públicas em âmbito governamental, o que leva a crer que a concretude da proposta de sustentabilidade exige a necessidade da materialização de investimentos em infraestrutura e serviços básicos, capazes de favorecer melhorias nas condições de vida dos moradores das RESEX e áreas de entorno. As análises de autores amazônidas como Costa (2009), Ferreira (2002), Silva (2007) e Simonian $(2007 ; 2004)$ permitem uma base teórica de determinado aspecto da realidade amazônica, em especial a que aborda a questão educacional enquanto Política Pública imprescindível para o desenvolvimento, melhoria da condição de vida das populações tradicionais e a manutenção das RESEX.

Também, trabalha-se com o conceito de resistência social e política quanto às populações que residem nas RESEX e à questão educacional na RESEX Marinha de Gurupi-Piriá. Nessa direção, as discussões de Abélès \& Badaró (2015), bem como de Rea Rodriguez et al., (2015) são instigantes. Abélès \& Badaró (2015, p. 62) inspiram-se em Foucault para enfatizar que os seres humanos são sujeitos de direitos e integram uma "identidad indivisa", sendo então parte de um "[...] sujeto nuevo de la soberania biopolítica". Os outros três autores trabalham com a noção de ação conflituosa, o que interessa à discussão ora empreendida.

Destarte, o enfoque deste artigo é o das Políticas Públicas Educacionais (PPE), com ênfase nas desenvolvidas com as populações tradicionais pesqueiras da RESEX Marinha Gurupi-Piriá. No sentido de fundamentar teoricamente o estudo, buscaram-se na literatura conceitos fundamentais para a compreensão da problemática em questão, como de PPE, unidade de conservação (UC) e educação para o desenvolvimento sustentável. Allegretti (1994; 2002), Sauvé (1997), Adorno (2000), Simonian (2004; 2007), Souza (2006) e Gadotti (2009) serviram de base enquanto abordagem analítica.

$\mathrm{O}$ estudo em questão partiu do seguinte questionamento: que PPE vêm sendo pensadas e implementadas para contemplar as necessidades e 
perspectivas das populações que vivem dentro das áreas de ocupação extrativista da RESEX GurupiPiriá? De que maneira está sendo viabilizada a participação efetiva das populações tradicionais no processo de elaboração e implementação de tais políticas de modo a garantir o atendimento de suas demandas socioeconômicas e, ao mesmo tempo, promover o uso sustentável dos recursos naturais existentes nessa UC?

Pretende-se, assim, levantar alguns questionamentos em torno das implicações da ausência de uma PPE que reconheça as especificidades do modo de vida das populações tradicionais pesqueiras das comunidades praianas da RESEX Marinha Gurupi-Piriá. Intencionase, ainda, conhecer e explicar a dinâmica da educação no contexto dessa UC. Por fim, tentou-se identificar/analisar quais são as políticas públicas que se encontravam em elaboração/execução na as localidades escolhidas para a pesquisa, precisamente as com vistas às propostas sustentáveis.

Por se tratar de uma pesquisa qualitativa, embasada nos ensinamentos de Godoy (1995) e na pesquisa de campo, e considerando as perspectivas analíticas de Malinowski (1978) e Oliveira (1996), é que se fez uso de questionário e entrevistas, além de observação participante. Ainda, desenvolveuse a pesquisa em meses alternados dos anos de 2013 e 2014, nas vilas de Apeú Salvador, Itacupim e Taperebateua. Os critérios de inclusão dessas localidades se justificam pela importância ambiental e estratégica de seus habitantes no município de Viseu e dentro da RESEX Gurupi-Piriá. Também, devido à ausência de políticas públicas específicas ${ }^{1}$.
O que se segue é uma discussão conceitual breve acerca da categoria analítica PPE, UC e educação para o desenvolvimento sustentável. Em seguida, empreende-se uma discussão em torno da educação formal, institucionalmente constituída pela escola, e das PPE implementadas na área. Também, analisam-se os desafios para a implementação de uma educação que corresponda à realidade e à proposta de sustentabilidade das vilas da UC.

\section{Políticas públicas educacionais}

A discussão acerca das políticas públicas tem sido objeto de estudos e pesquisa para a academia, instituições governamentais e centros de pesquisas. Trata-se de uma problemática com pontos de vista, compreensões e cenários diferenciados. De acordo com Souza (2006), as políticas públicas estão ligadas, na sua essência, fortemente ao Estado, pois é esse que determina como os recursos serão usados para o benefício dos cidadãos.

Para uma compreensão maior acerca da temática, Souza (2006, p. 26) apresenta seu entendimento sobre as políticas públicas, como sendo a área de conhecimento que visa, concomitantemente,

colocar o governo em ação e/ou analisar essa ação (variável independente) e, quando necessário, propor mudanças no rumo ou curso dessas ações e ou entender por que o como as ações tomaram certo rumo em lugar de outro (variável dependente).

\footnotetext{
${ }^{1}$ Principalmente, aquelas que impõem consequências profundas à educação e à qualidade de vida dos usuários da RESEX. Aliás, o mesmo pode ser dito em relação aos que habitam as áreas de entorno dessa UC.
} 
De acordo com Teixeira (2002, p. 2), “as políticas públicas são diretrizes, princípios norteadores de ação do poder público; regras e procedimentos para as relações entre poder público e sociedade, mediações entre atores da sociedade e do Estado". Segundo esse estudioso, elas visam resolver os conflitos ligados aos bens públicos e dar respostas às demandas sociais, por meio do sistema político. Dentre as exigências sociais listadas inúmeras vezes, estão: educação, saúde, assistência social, segurança, saneamento, habitação, entre outras.

Conforme Teixeira (2002), a elaboração de políticas públicas exige a necessidade de definir quem decide o quê, quando, com que consequências e para quem. Todavia, tais definições estão relacionadas à natureza do regime político, ao nível de organização da sociedade civil e à cultura política contemporânea. Com isso, evidencia-se a necessidade do estabelecimento de um diálogo coletivo durante a construção e implementação da política pública, sem desconsiderar os arranjos constituintes do contexto, para que, assim, o Estado delibere políticas públicas que produzirão resultados ou mudanças reais no cotidiano do cidadão.

Para Höfling (2001, p. 31), as políticas públicas sociais tratam de "ações que determinam o padrão de proteção social implementado pelo Estado, voltadas, em princípio, para a redistribuição dos benefícios sociais visando à diminuição das desigualdades estruturais produzidas pelo desenvolvimento socioeconômico". Desse modo, Höfling (2001) compreende que as políticas públicas são de responsabilidade do Estado, quanto à sua elaboração, execução e manutenção; conforme o autor, elas são construídas com base na tomada de decisões que envolvem órgãos públicos, diferentes organismos e agentes da sociedade relacionados à política implementada. É nesse processo que as políticas educacionais são produzidas.

Assim, de acordo com Azevedo (2001), as políticas educacionais implicam, como as demais políticas públicas, escolhas e decisões que envolvam indivíduos, grupos e instituições. Logo, não são obras de ações abstratas, mas frutos da correlação entre as forças sociais, que se articulam para defender seus interesses. De todo modo, para se compreender o funcionamento das políticas públicas educacionais, é necessário que se faça uma análise que vá além das questões ligadas à definição conceitual.

De maneira geral, as políticas educacionais enquanto políticas públicas têm que ser pensadas como investimentos de combate à exclusão social. Segundo o entendimento de Gusmão (2013), educação de qualidade é um direito a ser desfrutado por todos. Isso implica garantia da universalização do acesso e permanência na escola, equidade de resultados em provas padronizadas e introdução do contraponto das diversidades; estando essas premissas fundadas no valor de decrescimento da desigualdade.

Assim, há de se pensar na possibilidade de resistência social e/ou política das populações humanas envolvidas em tal processo, mesmo que existam fragilidades quanto ao capital social local (Putnam, 2002). Para Abélès \& Badaró (2015, p. 63), "a diferencia de la soberania tradicional caracterizada por el poder de producir la muerte o de dejar vivir, el poder a partir de ahora se define por su capacidade para hacer vivir o dejar morir". Porém, como se depreende de Rea Rodriguez et al. (2015) e com Simonian (2007), os conflitos ainda permeiam e muito as realidades socioculturais, prin- 
cipalmente as de características locais.

A busca é por políticas públicas que reorganizem a sociedade no sentido positivo, notadamente, quanto aos princípios de distribuição justa dos bens materiais e culturais. Isso de modo a construir a cidadania plena a partir do envolvimento e da participação social no debate de formulação, implementação e avaliação das políticas públicas.

\section{Unidades de conservação e a educação para o desenvolvimento sustentável}

O processo da expansão da fronteira capitalista do país sobre a Região Amazônica imposto pelo governo federal resultou, a partir de meados do século XX, e no entender de Léna \& Oliveira (1991), Allegretti (1994), D’Incao (1994) e Maciel (1999), num processo de desarticulação da atividade extrativista, o qual causou danos socioeconômicos e ambientais enormes às populações locais. Em meio a tal contexto, surgiu o movimento dos seringueiros no Acre contrários ao avanço da política desenvolvimentista implementada na região.

A reação à política desenvolvimentista é marcada por conflitos violentos, seguidos de denúncia de abandono, ameaças e péssimas condições de trabalho, que debilitavam os seringueiros ao longo de anos. Em resposta, na década de 1980, iniciou-se uma reorientação das políticas governamentais para a Amazônia, que preconizava os preceitos da sustentabilidade como estratégia nova de desenvolvimento, conforme Maciel (2003). Essa proposta se materializou com a instituição dos Projetos de Assentamento Agroextrativistas (PAE), em 1987, e as RESEX iniciadas a partir de 1990 pelo Decreto no 98.897 .

Conforme destacam Allegretti (1994) e Menezes (1994), as UC surgem como alternativas de exploração racional dos recursos naturais, como também de conservação da biodiversidade e mitigação do problema da especulação fundiária na região. São ações resultantes, segundo Allegretti (2002), do imobilismo do governo na implantação dos PAE e da pressão internacional em torno da preservação de florestas. Essa modalidade nova de uso da terra, que pressupõe a preservação da biodiversidade, estendeu-se, com a participação ${ }^{2}$ ativa das populações tradicionais que a integram, para além da floresta amazônica.

Com tamanha e igual importância, foram criadas, a partir do início dos anos 1990, as RESEX marinhas ${ }^{3}$. São UCs constituídas em áreas litorâneas, integrando, territorialmente, além de áreas florestais de terra firme, áreas marinhas, estuarinas e seus usuários, dependentes, principalmente, de áreas

\footnotetext{
${ }^{2}$ Em uma abordagem conceitual sobre participação, muitos foram os pensadores a se debruçarem sobre o tema. As contribuições podem ser apanhadas tanto em estudos clássicos como contemporâneos. A título de exemplo, podem ser citados os trabalhos de Aron (1993), Bordenave (2007), Gohn (1999), entre outros. De acordo com Medina (1994), o termo participação tem sua origem na palavra "parte", ou seja, significa fazer ou tomar parte de algum grupo ou associação, ou ainda, pode-se atribuir o termo ao processo de tomar parte em algum tipo de atividade ou negócio. É possível afirmar, ainda, que participar significa ter parte em algo, fazer diferença, contribuir para construção de algo tendo em vista um futuro melhor.

${ }^{3}$ Como subcategoria das RESEX, as RESEX marinhas estão definidas no artigo 18 do Sistema Nacional de Unidades de Conservação da Natureza (SNUC), Lei no 9.985, de 18 de junho de 2000, como: áreas utilizadas por populações extrativistas tradicionais, cuja subsistência baseia-se no extrativismo e, complementarmente, na agricultura de subsistência e na criação de animais de pequeno porte, e tem como objetivos básicos proteger os meios de vida e a cultura dessas populações, e assegurar o uso sustentável dos recursos naturais da unidade (Brasil, 2000).
} 
de manguezais, rios, igarapés e baías das quais extraem peixes, crustáceos e moluscos para sua subsistência. Como posto por Batista \& Simonian (2013), a reprodução socioeconômica dos usuários dessas UCs está diametralmente ligada ao manejo dos recursos marinhos, fluviais e ou lacustres, bem como da floresta de manguezal disponíveis na área.

Isso embora, para o movimento social de base, a instituição das UC represente uma conquista em termos de políticas públicas direcionadas à proteção da biodiversidade e ao reconhecimento das populações tradicionais que fazem uso dessas áreas. Nessa perspectiva, muito há que ser feito em termos de políticas sociais que possam contribuir para a gestão do bem comum, para o exercício da cidadania com propósito de construir um estilo novo de vida, sob a ótica da sustentabilidade e da equidade social. Para Aragón (2013), as RESEX são áreas a serem fortalecidas e ajudadas com medidas que viabilizem sua manutenção e desenvolvimento sustentável.

Sob essa perspectiva e conforme Silva et al. (2013) e Simonian (2004), a UC representa uma possibilidade de uso sustentável dos recursos naturais e uma estratégia para que as populações tradicionais exerçam o controle sobre a dinâmica de transformação local. Para tanto, sua efetivação demanda a implementação de políticas públicas sociais a partir da complexidade dessas realidades e desenvolvidas em âmbito oficiais, evitando, assim, o centralismo e a burocratização governamental do processo. Dentre essas políticas, está a busca por uma educação voltada ao desenvolvimento sustentável ${ }^{4}$ direcionada ao fortalecimento e promoção das populações tradicionais das RESEX marinhas.

Nos termos de Gadotti (2009), a educação sustentável não canaliza seus esforços, apenas a constituição de uma relação saudável com o ambiente. A partir dela, há a preocupação com o sentido profundo do que se faz com a existência, a partir da vida cotidiana. Essa é uma abordagem que traz entre seus objetivos o empoderamento dos sujeitos "para agir por mudanças sociais e ambientais positivas" (UNESCO, 2005, p. 33). Um enfoque que poderá levar à compreensão do jogo de forças, a interesses e implicações acerca das condições de vida dos moradores e usuários da RESEX.

AUNESCO indica, no documento "Década das Nações Unidas da Educação para o Desenvolvimento Sustentável - 2005-2014" (Sauvé, 1997), um conjunto de questões que dão consistência prática ao conceito de educação para o desenvolvimento sustentável, ou a educação para a sustentabilidade, como se depreende de Sauvé (1997) e Sterling (2001). De acordo com UNESCO (2005, p. 32), "Educação para o desenvolvimento sustentável focaliza, assim, os princípios e valores transmitidos por intermédio da educação e está voltada [...] para todos os tipos de ensino".

Ainda, conforme Gadotti (2009), a proposta arrolada no documento pode contribuir para transformar os programas educacionais atuais, no sentido de promover o conhecimento, as competências, as habilidades, os princípios, os valores e as atitudes relacionadas à sustentabilidade. Decerto que, para Gadotti (2009, p. 62), "a

\footnotetext{
${ }^{4}$ A Educação para o Desenvolvimento Sustentável (EDS) é uma dimensão da educação que visa equilibrar o bem-estar humano e econômico com as tradições culturais e o respeito aos recursos naturais (UNESCO, 2017).
} 
preservação do meio ambiente depende de uma consciência ecológica e a formação da consciência depende da educação". Isso com vistas à constituição de uma cultura de paz e sustentabilidade, capaz de enfrentar a barbárie, de pôr fim à miséria, ao analfabetismo, à dominação política e à exploração econômica; enfim, uma educação emancipatória sob a perspectiva adorniana ${ }^{5}$.

Então, cabe pensar em uma proposta que leve em conta a educação para a sustentabilidade, contudo, sem negar a importância das demais correntes de análise da problemática. Precisamente, isso com base em uma abordagem que busque enfatizar a dimensão ecológica da crise ambiental, as práticas sociais e a construção de um futuro sustentável. Assim, para esse caso específico, que são as RESEX marinhas, aposta-se em uma educação que teria suas bases assentadas na construção do senso de autonomia e pensamento crítico conforme ensinamento de Adorno (2000).

Seria, de acordo com a UNESCO (2017, p. 7), uma educação que estimule os partícipes ${ }^{6}$ desse processo quanto à capacidade de tomar "decisões informadas e adotar ações responsáveis para assegurar a integridade ambiental, a viabilidade econômica e uma sociedade justa". Aliás, o pensamento voltado para a sustentabilidade exige, dentro do processo educativo das áreas de UC, segundo Costa (2009), que se pense em uma educação construída a partir da terra, dos rios, da floresta, considerando conflitos e divergências desse espaço.

Esse é um enfoque que possivelmente contri- buirá, conforme a UNESCO (2017, p. 32), para que os sujeitos reflitam "sobre sua região no desenvolvimento de sua própria identidade, compreendendo os papéis que os ambientes naturais, sociais e técnicos tiveram na construção de sua identidade e cultura". Isso significa dizer que não é mais possível pensar na definição do futuro da Região Amazônica, de acordo com Silva \& Nascimento (2015), sem considerar as características inerentes às populações tradicionais amazônicas e suas particularidades culturais no processo educacional. Note-se, inclusive, que essa perspectiva analítica vem sendo construída há tempos, conforme proposto por Simonian (2000; 2007), dentre outros autores.

Diante desse contexto teórico, as análises sustentadas nos resultados da pesquisa mostram como se estruturaram as UC. E, do mesmo modo, como se implementam as PPE. Ainda, como vem ocorrendo o debate sobre a educação para o desenvolvimento sustentável em áreas de ocupação de populações tradicionais pesqueiras na Amazônia.

\section{Políticas educacionais e os desafios da educação para a sustentabilidade na RESEX Gurupi-Piriá}

A RESEX Marinha Gurupi-Piriá ocupa, territorialmente, $15 \%$ do município de Viseu, como se vê na Figura 1. É a maior RESEX marinha da costa brasileira, com aproximadamente 74 mil hectares de área. Em termos de recursos naturais,

\footnotetext{
${ }^{5}$ De acordo com o pensamento de Adorno (2000), a educação deve fomentar a capacidade de superar o conformismo e a indiferença, a capacidade de experimentar, de arriscar, de se fazer diferente dos outros, de romper com a submissão resultante da vida social.

${ }^{7}$ Nesse artigo, os partícipes considerados são: crianças, adolescentes, professores, pescadores, marisqueiras, donas de casa, lideranças comunitárias, entre outros.
} 


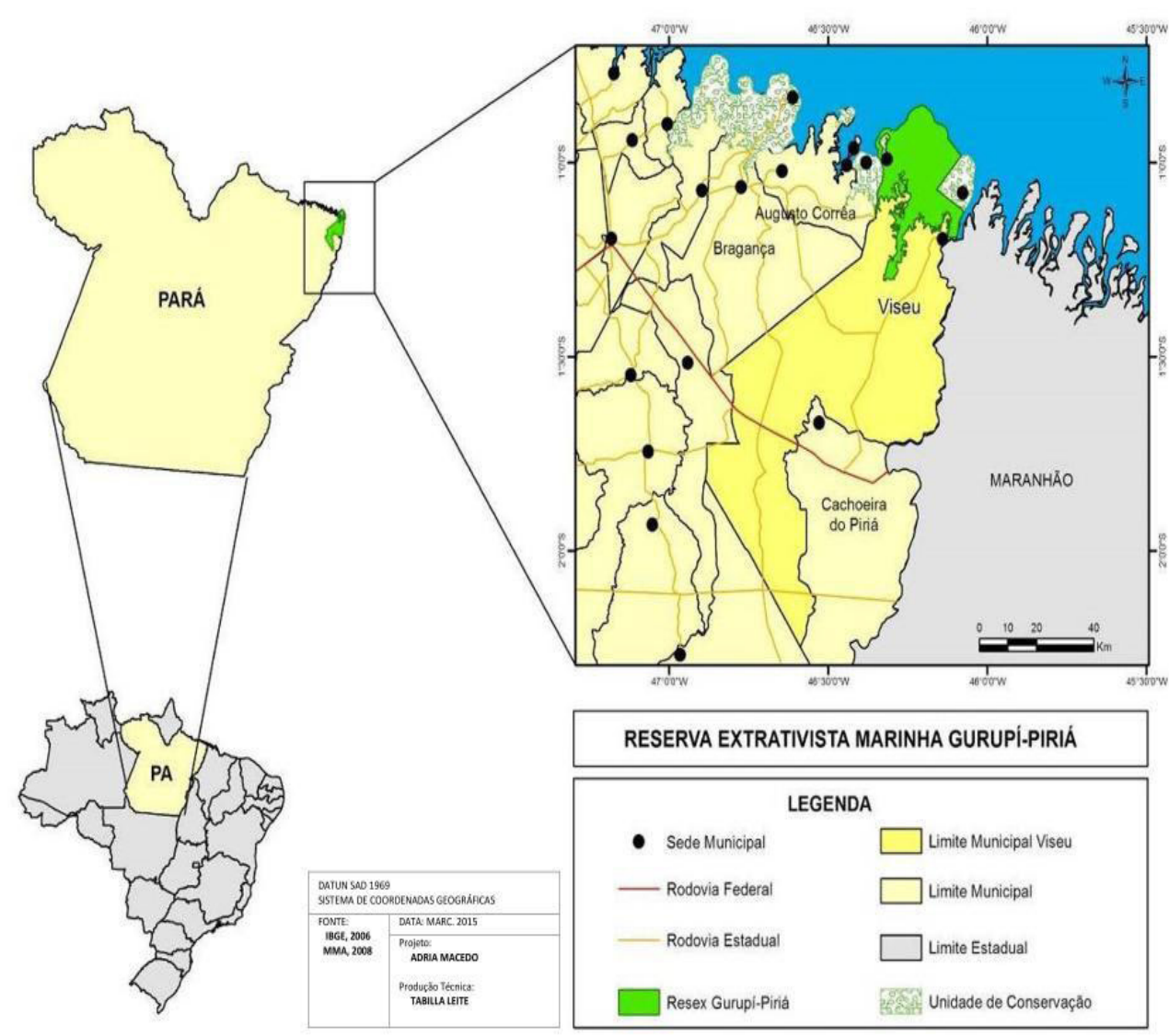

FIGURA 1 - Localização da RESEX Gurupi-Piriá.

FONTE: Macedo, pesquisa de campo (2014); IBGE (2006); MMA (2008). Adaptado por Tabilla Leite.

é coberta por um ecossistema de manguezal de mais de 40 mil hectares, distribuídos entre campos naturais, floresta de mangue, praias arenosas e dunas. Sob a influência da RESEX estão 47 vilas e três bairros da cidade de Viseu, sendo que 32 dessas ocupações estão dentro da UC; as outras 14 vilas e a sede do município de Viseu ficam no seu entorno.

As localidades de praias (Ilha de Apeú Salvador, Taperebateua, Itacupim) fazem parte de um conjunto de ilhas que estão localizadas dentro da
RESEX Marinha Gurupi-Piriá. Elas são formadas por cerca de 30 a 80 famílias, possuem uma realidade diferenciada pelo ambiente e pela distância daquelas de terra firme. Para Sousa (2000), as características ecológicas das localidades praianas, terreno arenoso e com alto teor de salinidade, dificultam a prática da agricultura, entretanto, favorecem as atividades da pesca. Assim, os habitantes das ilhas ou os praianos são constituídos de pescadores artesanais em tempo integral. 
Acerca da educação, conforme consta no resultado do Índice de Desenvolvimento da Educação Básica (IDEB, 2013), o município de Viseu ocupa a 5.046 posição, entre os 5.565 do Brasil. Isso quando são avaliados os alunos dos anos iniciais do ensino fundamental, e na $3.588^{\mathrm{a}}$, no caso dos alunos dos anos finais do ensino fundamental. Como se depreende do Portal ODM (2010), quando comparada sua posição com os 143 municípios do estado Pará, Viseu está na 111aㅗ posição nos anos iniciais, e na $36^{\mathrm{a}}$ nos anos finais.

De acordo com dados estatísticos levantados pela Secretaria Municipal de Educação (SEMED) de Viseu, o município registrou, no ano de 2013, um total de 20.605 alunos matriculados em sua rede de ensino, conforme Tabela 1. Em se tratando das localidades praianas de Apeú Salvador, Taperebateua, Itacupim da referida RESEX, os dados estatísticos registraram 322 matrículas para o ensino fundamental.

Apesar dos avanços para a educação brasileira, em especial a educação do campo, presentes na Constituição (Brasil, 1988), na Lei de Diretrizes e Bases da Educação (LDB) (Brasil, 1996), em legislações, decretos e pareceres, seus propósitos ainda não atingiram a sociedade nacional como um todo, no sentido da transformação. Para Saviani (2009), embora essas políticas públicas implementadas pelo governo federal tratam de vultosos investimentos educacionais, ainda assim estão aquém de representarem a garantia da qualidade da educação. Desse modo, estão longe da solução dos problemas estruturantes da educação no país, sobretudo, nas regiões que contam com heterogeneidade produtiva, ambiental, sociocultural e territorial, como na Amazônia.

Na RESEX Marinha Gurupi-Piriá, a questão educacional exige, de acordo com a análise dos dados coletados e a fala dos interlocutores, a necessidade de uma revisão profunda acerca dos métodos de ensino, formato curricular, aparelhamento desses espaços com materiais didáticos e equipamentos pedagógicos. Constatou-se, ainda, a ausência de uma proposta educacional que busque atender às populações tradicionais pesqueiras respeitando suas identidades construídas a partir da dinâmica mantida com o mar. Em depoimento, o pescador artesanal José Nazareno Lopes ${ }^{7}$ asseverou que "quem faz o horário do pescador é a maré; a escola não reconhece isso"

TABELA 1 - Demonstrativo de matrículas para 2013 do município de Viseu-PA

\begin{tabular}{cc}
\hline Níveis da Educação & № de matriculas \\
\hline Creche & 291 \\
Educação Infantil & 2.680 \\
EF Anos Iniciais & 9.700 \\
EF Anos Finais & 4.341 \\
E. Médio & 2.491 \\
EJA & 3.598 \\
Educação Especial & 0 \\
\hline
\end{tabular}

FONTE: Censo Escolar/INEP (2013), SEMED (2013).

${ }^{7} \mathrm{O}$ sr. Nazareno tinha 33 anos de idade quando concedeu a entrevista em 2014. 
O tempo e o calendário da escola tradicional convergem com o tempo da maré, situação que tem sido denunciada timidamente por educadores, educandos, lideranças e pelo movimento social na base comunitária, a Associação dos Usuários da RESEX Marinha de Viseu (ASSUREMAVE). Conforme os moradores, os pais, as mães e os alunos do local, os problemas relacionados à educação são muitos e urgentes. Isso tem reforçado os conceitos de "ações conflituosas" e "deixar viver", o que em tese implica transformações, mas que tem sido obstaculizado pelo modo persistente de se fazer políticas públicas que é o da dominação ${ }^{8}$.

Não se trata apenas de viabilizar a presença da escola nesses espaços, mas também de destacar o quanto é importante a implantação de uma educação formal diferenciada que atenda às necessidades reais atuais de sustentabilidade e à cultura dos povos das marés, definidas por meio das políticas públicas sociais. A exemplo da Escola das Águas, implementada na Bahia no ano de 2011. De acordo com Alves \& Ubiratan (2017), a Escola das Águas é uma experiência educacional pensada pelo Movimento dos Pescadores Artesanais. E isso com vistas à elevação da escolaridade, à conclusão do ensino básico, à formação política e à qualificação técnica, em um processo educativo voltado à realidade vivenciada no território da pesca artesanal.

Por conseguinte, as comunidades pesqueiras da RESEX Marinha Gurupi-Piriá aparecem como um campo fértil para implantação de um modelo educacional que venha fomentar os desejos de mudanças histórico-culturais, indispensáveis ao processo de desenvolvimento humano. Igualmente, contribuirá no fortalecimento de um movimento social politicamente autônomo e comprometido com a construção de uma sociedade mais justa, solidária e sustentável. Pois, como ressalva Hamilton (2002), a educação pode ser tomada como um influente instrumento de empoderamento social.

De todo modo, a precariedade estrutural extrema das escolas nas vilas de Apeú Salvador, Itacupim e Taperebateua foi apontada pelos interlocutores como o problema mais grave a ser ali superado. O risco de desabamento tem deixado professores, alunos, e demais funcionários em alerta constante. Os depoimentos que seguem são ilustrativos a esse respeito; segundo Natanael Gonçalves Sousa, 15 anos de idade em 2014, aluno da 7 a série do ensino fundamental, "a escola é muito quente, as paredes estão quase caindo, o vento traz a poeira da rua para dentro da sala"9. O problema da estrutura física da escola em Taperebateua é tão grave, diante dos olhos da comunidade, que esses a nomearam, pejorativamente, de "forno"10.

Em Apeú Salvador, a situação não se difere. De acordo com o pescador artesanal e liderança comunitária, Antônio Maria Rodrigues da Silva, de 35 anos em 2014, "a escola tem oferecido riscos aos alunos. Por ser muito antiga, de madeira e dois andares; ela não suporta mais os ventos fortes da praia. A qualquer hora ela poderá desabar" ${ }^{11}$. Ao

\footnotetext{
${ }^{8}$ Como posto por Macedo (2015), a prisão de pais e professores in loco levados a Viseu é exemplar a respeito, eles apenas queriam uma educação melhor.

${ }^{9}$ Informação verbal, 2014.

${ }^{10}$ Os telhados das escolas da RESEX são de amianto. Em Apeú Salvador, parte dos moradores tem optado, inclusive, pelo uso das telhas de amianto para a construção das paredes externas e internas das residências. De acordo com interlocutores locais, o custo é menor em relação à aquisição da madeira.
} 
ser questionada sobre as condições infraestruturais péssimas das referidas escolas, a secretária da SEMED-Viseu esclarece que elas estão incluídas no projeto municipal de reformas; que têm sido realizadas prioritariamente em unidades com problemas de infraestrutura mais urgentes do que os encontrados nas localidades investigadas.

De todo modo, em campo, foi possível observar que se tratam de unidades escolares muito antigas, que nunca passaram por qualquer tipo de reforma, e que oferecem riscos de desabamento. Infere-se que se trata de uma política pública de importância, mas que vem ocorrendo a passos lentos dentro das vilas da RESEX, isso a se considerar o grau de urgência e riscos que essas unidades têm oferecido. Além do que, segundo depoimento dos professores, alunos e pais, a revitalização desses espaços contribuirá significativamente na melhoria das condições infraestruturais, podendo refletir positivamente no processo ensino aprendizado desse alunado.

A formação de professores (ou a carência dela) também se configura como fator agravante da questão educacional na RESEX Gurupi-Piriá. Dos professores em exercício no ensino infantil e nas séries iniciais do ensino fundamental ( $1^{\circ}$ ao $5^{\circ}$ o ano/9ㅇ), muitos ainda não têm graduação e outros encontram-se cursando-a. Quanto aos anos finais do ensino fundamental (6o ao $9^{\circ}$ ano/9o ou $5^{\text {a à }} 8^{\text {a }}$ séries), professores entrevistados afirmaram que "A

\footnotetext{
${ }^{11}$ Informação verbal, 2014.
}

${ }^{12}$ Informação verbal, 2014. Prof. ${ }^{a}$ Wanderléia J. M. Tavares.

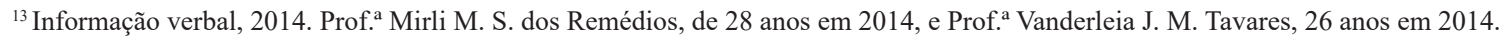

${ }^{14}$ Informação Verbal, 2014. Prof. ${ }^{\text {a }}$ Rosa Helena, 45 anos em 2014.

${ }^{15}$ Muitos professores recorrem às faculdades particulares pela flexibilidade nos horários e valor "baixo" das mensalidades. Algumas faculdades citadas pelos entrevistados são: Pan-Americana (FAEM), Universidade do Vale do Acaraú (UVA), Faculdade Evangélica do Piauí (FAEPI) e Faculdade Latino-Americana de Educação (FLATED).

${ }^{16}$ Informação verbal, 2014.
SEMED não costuma realizar cursos de formação continuada para os professores do $6^{\circ}$ ao $9^{\circ}$ ano ao longo do ano letivo"12.

Conforme constatado, o momento mais próximo de uma "formação continuada" ofertada aos docentes que atuam nas séries finais do ensino fundamental seria o período de realização do planejamento anual. De acordo com os professores, trata-se do momento de "passar a limpo o plano de curso do ano anterior. Sem acréscimo de novas propostas metodológicas"13. Dentre outros, tal depoimento pode ser consolidado com a fala da responsável pela coordenação Geral da Educação de Jovens e Adultos (EJA), no município: “o que tá faltando para melhorarmos o nosso sistema de ensino é planejamento e formação. Nossos professores raramente planejam suas atividades; são poucas as formações realizadas durante o ano letivo"14.

Na perspectiva de alcançarem o nível superior ou manterem-se atualizados, mas sem ter que abandonar o emprego ou se distanciar da família por longos meses, parte dos professores arrolados na pesquisa tiveram ou tem que recorrer aos cursos semipresenciais em faculdades particulares ${ }^{15}$. Em depoimento, a professora Vanderliza de Sousa dos Santos - de 33 anos em 2014 - reconhece que "não tenho como deixar minha família aqui na praia (em Apeú Salvador) para ir cursar universidade o mês inteiro na cidade. Por isso, optei pela universidade particular"'16. 
De certo que muitos professores que atuam nas comunidades da RESEX Gurupi-Piriá, e mesmo no restante do município de Viseu recorrem à formação acadêmica de custo "baixo" e calendário flexível. Mesmo diante das dificuldades financeiras, de deslocamento e das poucas oportunidades que reúnem para participar de cursos e oficinas pedagógicas ofertados pela SEMED, os professores têm assumido interesse pela busca de formação e de novos conhecimentos sobre as questões relacionadas ao processo educativo.

Outra situação observada em campo referese ao atendimento de alunos com necessidades educacionais especiais. Em uma das comunidades pesqueiras da RESEX foi observado o caso de uma professora que atendia uma turma multissérie (4은 e $5^{\circ}$ ano $\left./ 9^{\circ}\right)$ com cinco alunos com necessidades educacionais especiais. Pelo que a professora informou ${ }^{17}$, ela se formou "no antigo magistério, pouca coisa se falou sobre educação especial, acho que a SEMED deveria oferecer formação ou acompanhamento pedagógico que auxilie nossas atividades com essas crianças". Em consulta aos dados do Censo da Educação Básica, 2013, da rede municipal ensino de Viseu, não se constatou o registro de matrículas de tais alunos no sistema do MEC.

É pertinente dizer que a administração pública municipal de Viseu precisa dar uma atenção maior ao processo de inserção e efetivação de políticas públicas educacionais que atendam a pessoas com deficiência dentro das comunidades da RESEX e no restante do município. Segundo estudos de Meletti \& Ribeiro (2014), a década de 1990 marca a adesão do Brasil às orientações internacionais que tratam das ações sobre necessidades educativas especiais. Isso devido aos acordos firmados na Conferência Mundial de Educação para Todos (1990) e na Declaração de Salamanca (1994), o que resultou da Conferência Mundial Sobre Necessidades Educacionais Especiais (1994).

As observações in loco e as entrevistas com diretores de escolas, líderes comunitários locais e alunos mostraram que não há na prática pedagógica "a interconexão dos conteúdos formais ressignificados à dinâmica da atividade pesqueira". Não se observou qualquer planejamento ou iniciativa pedagógica que tome a tradição e cultura da pesca artesanal como elemento base de conhecimento. Situação que remete a uma reflexão acerca da elaboração de uma PPE inovadora que proporcione uma interface entre currículo formal, prática pedagógica e identidade cultural dessas populações. Nos termos de Alves \& Gonçalves (2017), isso viabilizará a valorização dos conhecimentos dos sujeitos ali presentes e o fortalecimento da identidade pelo território pesqueiro.

No entendimento de D'Incao (1994), a diversidade sociocultural e produtiva das populações tradicionais tem que ser levada em consideração, precisamente, como variável, ao se planejar e implementar políticas públicas sociais, especialmente as de cunho educacional. Nos termos de Silva (2007), de um modo geral, o que ainda se tem dentro e no entorno das UC amazônicas são processos educacionais dissociados da realidade socioeconômica, cultural e ambiental das populações tradicionais.

${ }^{17}$ Informação verbal, 2014. Prof. a Doracir Ramos, de 42 anos em 2014. 
Notadamente, elementos socioculturais e produtivos dos pescadores artesanais, marisqueiras e caranguejeiros ainda não foram captados pelo sistema de ensino do município de Viseu ou mesmo por outras realidades similares. Entretanto, isso já ocorre na experiência inovadora da Escola das Águas, na Bahia.

O saber do outro representado e materializado culturalmente em aspectos positivos que enfatizam a proteção do ambiente natural, o relacionamento forte com o mar e a floresta de manguezal; o uso medicinal de suas plantas e raízes; seu artesanato e suas festividades religiosas não foram visualizados na proposta pedagógica de ensino. Entretanto, de acordo com Acevedo-Marin \& Castro (1999) e com Simonian (2005; 2007), esses são aspectos de relevância para se entender como essas populações se organizam, agem sobre a natureza e tornam permanentes seus sistemas tradicionais de manejo. Apesar disso, precisam ser tomados como campo educativo por excelência.

É a partir dessa realidade, associada ao conhecimento sistematizado, que poderão ser ampliados, fortalecidos e efetivados valores e mentalidades direcionados ao exercício de práticas sustentáveis e à manutenção do modo de vida das populações tradicionais dentro das UC. Decerto, de acordo com os ensinamentos de Gadotti (2009, p. 62), "a preservação do meio ambiente depende de uma consciência ecológica e a formação da consciência depende da educação". E isso torna a reflexão acerca dos comportamentos, revelados a seguir, imprescindíveis ao processo de construção de políticas públicas sociais inovadoras para a área.
A problemática da sustentabilidade socioambiental vem sendo discutida em âmbito mundial. Rea Rodriguez et al. (2015) trazem, dentre outras pesquisas nessa direção, experiências da população que vive próxima ao rio San Pedro, em Nayarit, no México. Ela tem enfrentado a implantação do Projeto Hidroelétrico Las Cruces, iniciado na perspectiva top down. Por se posicionar contra, articularam-se com apoiadores para resistirem e até lograrem uma ação participativa, e assim, abrirem portas a determinados acordos para que superassem os muitos aspectos negativos. Essa experiência pode, como outras, sugerir possibilidades de participação para os ilhéus da RESEX de Viseu.

Como posto por Vergara Filho \& Silva (2001), os filhos pequenos acompanham, comumente, os pais nas pescarias, como ajuda familiar e como aprendizado para o futuro. Em depoimento, a responsável da escola de Apeú Salvador ressalta que "muitas das crianças que desistem da escola são meninos. Eles preferem ir para a maré; trabalham ajudando os adultos na pescaria" ${ }^{18}$. Jacó Silva Tavares, de 16 anos, e estudante da 4⿳亠丷厂 série (5o ano/9) relata de que gosta: "de estudar, o professor é bacana, mais prefiro a maré. É mais divertido e o dinheiro que ganho com a pescaria dá para comprar roupa e outras coisas; dá para ajudar aqui em casa".

Portanto, o referido estudo assinala que os índices elevados de reprovação, evasão ${ }^{19}$ escolar e analfabetismo funcional acentuam-se entre os jovens do sexo masculino nas localidades da RESEX Marinha Gurupi-Piriá. Infere, ainda, que a influência da atividade pesqueira, somada à questão

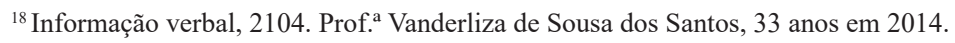

${ }^{19}$ Índice de evasão e reprovação escolar de acordo com dados do censo de 2013. Evasão: Escola Eduardo Costa Mendes, em Apéu Salvador, 16\%; Escola Prof. ${ }^{a}$ Angelina Oliveira, em Taperebateua, 15,9\%; Escola Anésio Machado, em Itacupim, 5,3\%. Reprovação: Escola Eduardo
} 
financeira e à ausência de uma PPE, direcionada a uma realidade marcada fortemente pelo ritmo das marés, têm influenciado sobremaneira a decisão de continuar ou não a frequentar a escola. Fato esse evidenciado, principalmente, entre jovens de $14 \mathrm{e}$ 20 anos de idade.

A adoção do modelo educacional citadino ${ }^{20}$ há muito prejudica crianças, adolescentes e jovens das localidades de base pesqueira na costa litorânea amazônica. Ao submeter essa realidade ao parâmetro educacional urbano, contrariam-se os preceitos constitucionais e legais que reconhecem a educação enquanto direito de todos, bem como $\mathrm{o}$ respeito às singularidades culturais e regionais (Brasil, 1988; Brasil, 1996). A negação desse direito tem contribuído para sustentar a manutenção de problemas sérios de caráter educacional para essa UC, assim como é evidente que o status quo percebido localmente não é uma realidade que se diferencia muito do restante do município de Viseu ou mesmo de outras partes e mesmo UC da Amazônia.

Conforme depoimento de usuários da RESEX, o envolvimento do Instituto Chico Mendes de Conservação da Biodiversidade (ICMBIO) com ações voltadas à educação ambiental é praticamente inexistente dentro das comunidades praianas da RESEX. Segundo o presidente ${ }^{21}$ da Associação dos Usuários da RESEX Marinha Gurupi-Piriá, "o ICMBIO, desde a criação da RESEX, nunca apresentou um projeto consistente, voltado à questão da educação ambiental; nem projeto para trabalhar a questão ambiental nas escolas das localidades praianas". As poucas ações realizadas por essa instituição dentro das áreas praianas se diversificaram.

Precisamente, tais ações públicas estiveram voltadas, nos últimos meses, à fiscalização e apreensão de apetrechos de pesca em atividade irregular; à atualização cadastral de usuários; ao repasse de informações sobre o Programa Bolsa Verde (PBV) e ao estabelecimento de acordo de pesca entre os curralistas ${ }^{22}$. Ainda, de acordo com a gestora da UC, as limitações de recursos materiais, financeiros e humanos - além das dimensões do território - não permitem o exercício de uma fiscalização sistemática de modo a coibir práticas predatórias, fato que se estende a outras UC, conforme Batista \& Simonian (2013), Costa (2009) e Silva (2007).

Note-se que isso engessa as possibilidades de implementação de outras políticas públicas, por exemplo, a de educação ambiental. É uma situação que, no contexto de UC, o papel a ser desempenhado pelo ICMBIO, entre outros, é de grande relevância por se tratar de um organismo responsável em propor, incentivar ações de proteção, pesquisa, educação e conservação dessas

Costa Mendes, $45 \%$ ( $1^{\circ}$ ao $5^{\circ}$ ano ) e $20 \%$ ( $6^{\circ}$ ao $9^{\circ}$ ano); Escola Prof. ${ }^{a}$ Angelina Oliveira, $45 \%$ ( $1^{\circ}$ ao $5^{\circ}$ ano) e não foi registrado reprovação nos anos finais ( $6^{\circ}$ ao $9^{\circ}$ ano), Escola Anésio Machado, $7 \%$ ( $1^{\circ}$ ao $5^{\circ}$ ano).

${ }^{20}$ Nas escolas da RESEX Marinha Gurupi-Piriá não se percebeu grandes diferenças em relação ao cotidiano de outras escolas, por exemplo, as escolas da área urbana da cidade da cidade de Viseu. Nas três observadas são realizadas atividades comuns, tais como: leituras e compilação de textos, algumas vezes ditados, outras vezes escritos de livros ou quadro negro; resolução de problemas matemáticos; enfim, aspectos muito simples quando considerada a emergência de formar cidadãos que assumam os debates políticos num contexto que sempre carece de novas lideranças e representatividade social qualificada.

${ }^{21}$ José Carlos Tavares, entrevista concedida em 2014.

${ }^{22}$ Curralistas ou curralheiros: pescadores que desenvolvem sua atividade pesqueira em currais de pesca. 
reservas. A pesquisa realizada na RESEX Marinha Gurupi-Piriá demonstra que é preciso aproximar as instituições que estão presentes nessa UC com vistas a construir projetos educativos que não só estimulem a participação qualificada, como construam e consolidem organizações voltadas para o controle social.

A tentativa de inovar o sistema educacional do município de Viseu ocorre via implantação de projetos como o Mais Educação, o Saberes da EJA, a adoção do sistema modular para séries finais do ensino fundamental em vilas de acesso difícil; com destaque para o Pacto Nacional pela Alfabetização na Idade Certa (PACTO) ${ }^{23}$, e a proposta de Pedagogia de Projetos. A SEMEDViseu apoia-se no PACTO, para incrementar a proposta de "Pedagogia de Projetos" (2013). De acordo com a SEMED, as ações só não são maiores e mais eficientes por conta dos poucos recursos repassados ao município.

De acordo, com o professor Elder Cardoso Brito $^{24}$, da vila de Taperebateua,

as formações feitas pelo Pacto e a metodologia de Projetos têm nos ajudado a melhorar o trabalho com as turmas. Me sinto mais preparado para trabalhar com as crianças; as aulas ficaram mais criativas após as formações.

Porém, o mesmo não se pode dizer das séries finais do ensino fundamental e EJA. Precisamente, a prioridade é dada para atividades escolares relacionadas às disciplinas regulares, como matemática, história, geografia, ciências etc., por meio da socialização abstrata.

Essas são escolas que conseguem, mesmo que de maneira precária, levar à frente uma proposta de educação de massa, de acordo com Nascimento (2001). Ensinam-se crianças, adolescentes, jovens e adultos a ler e escrever, mas com uma relação mínima com a temática ambiental, e as práticas e saberes existentes nas comunidades tradicionais pesqueiras da RESEX em questão. Observou-se que o desafio reside em estimular os professores para que levem tais questões para salas de aula, ou mesmo instigá-los a começar a relacionar tais assuntos às suas disciplinas.

Em que pese a discussão sobre a proposta de incorporação de alimentos in natura à merenda escolar, ainda não foi implementada no município de Viseu e, por conseguinte, nas escolas da Reserva. A base alimentar dessas escolas constitui-se sobretudo de produtos industrializados ricos em gordura, sal, açúcar e pobre em micronutrientes, como: achocolatados, mingau, macarrão, sopa, bolachas, biscoitos, enlatado e embutido (salsicha e mortadela). Apesar disso, para pais e alunos, trata-se de uma merenda "fraca, repetitiva e sem sustância" por não incorporar frutas, hortaliças e produtos da própria região, como o pescado no cardápio da merenda escolar.

O desejo e a vontade dos alunos de merendar alimentos diferentes aos que estão habituados não são considerados no instante da sua aquisição, apesar de os alunos e pais expressarem que gostariam de ter alimentos como o suco acompanhado de pão fresco, o leite com biscoito, frango, carnes e

\footnotetext{
${ }^{23} \mathrm{O}$ PACTO é um programa do governo federal que visa alfabetizar todas as crianças até os oito anos de idade, ao final do $3^{\circ}$ ano do ensino fundamental.

${ }^{24}$ Entrevista concedida em 2014.
} 
produtos do mar. Quando há merenda, os alunos permanecem durante quatro horas na escola; quando não há, o tempo de trabalho destinado às atividades pedagógicas é reduzido e, no mais das vezes, suprime-se o recreio e libera-se os alunos mais cedo.

Assim, com base nas observações in loco e em depoimento colhido em campo, é possível apontar para a emergência de um projeto pedagógico construído na/para as RESEX marinhas. De acordo com Silva (2007, p. 26), "mais do que qualquer outro espaço interiorano da Amazônia, as UC de uso sustentável devem dar respostas à questão educacional, considerada fundamental para a eficácia dos muitos processos de construção dessa nova proposta de desenvolvimento local". Enfim, uma educação capaz de forjar indivíduos emancipados, aptos a pensar, e pensar-se enquanto sujeitos históricos, produtores de sua própria história, como preconiza Adorno (2000).

\section{Considerações finais}

Com a instituição das RESEX marinhas e costeiras, no litoral brasileiro experimenta-se um padrão novo de gestão territorial, calcado no uso coletivo dos recursos do ecossistema de manguezal e recursos marinhos, a partir de modelos de utilização de áreas comuns. Nessa perspectiva, as RESEX são defendidas como modelos de sustentabilidade, posto que, por sua definição legal, elas apresentam condições de articular crescimento econômico, conservação dos recursos naturais e qualidade de vida. Ainda que possam representar uma conquista para a manutenção dos recursos naturais e reconhecimento das populações tradicionais locais, nessas UC há muito a se fazer para que alcancem a efetivação de seus objetivos.

Nesse sentido, uma medida importante que pode ser implementada - visando contribuir para a transformação dessa realidade - será a inserção de práticas pedagógicas novas pensadas a partir de sua realidade. Um modelo construído a partir do diálogo entre SEMED, Conselho Deliberativo da RESEX, bem como o Comitê de Base Comunitária, que integre a questão ambiental e as especificidades de sua condição de UC, como o respeito, a valorização do conhecimento e da cultura (Brasil, 2000) de áreas historicamente ligadas ao extrativismo de recursos marinhos.

Infere-se que a reflexão acerca das práticas socioculturais das populações tradicionais, a partir das práticas pedagógicas desenvolvidas nas unidades de ensino, é importante no sentido de considerar que essas são detentoras de um saber relevante para a formulação de propostas de desenvolvimento sustentável para a região. Precisamente, seria uma educação voltada ao fortalecimento dos usuários. Assim, elas seriam capazes de levar às populações tradicionais a percepção do sentido real dos processos de tomada de decisões, elaboração, planejamento e avaliação de políticas públicas voltadas ao desenvolvimento humano local.

Embora exista uma RESEX federal decretada dentro do território de Viseu, o tratamento recebido do governo federal continua sendo o mesmo dado a qualquer outro município, não havendo, segundo a SEMED-Viseu, projetos que considerem as especificidades dessa região. Também não há, por parte dessa secretaria, projetos voltados especificamente para trabalhar a realidade das comunidades pesqueiras da RESEX, nem parcerias 
entre o movimento social local dos pescadores artesanais, ASSUREMAVE e o ICMBIO no sentido de promover ações de educação ambiental às inúmeras comunidades tradicionais da RESEX Gurupi-Piriá.

Ao contrapor pontos de vista diferentes sobre educação e RESEX no município, parece haver poucos esforços ao diálogo entre do poder público municipal e as pessoas envolvidas na organização da RESEX. De um lado, a SEMEDViseu aparenta ter pouco interesse na questão; de outro, o movimento social e os moradores da Reserva denunciam a omissão e o descompromisso do poder público municipal e federal, especialmente em relação às comunidades pesqueiras. A questão política partidária é posta como a preocupação principal do município em detrimento de uma proposta de projeto educacional integrado que valorize as especificidades locais e que discuta a sustentabilidade e qualidade de vida.

Dentro do movimento social, existe um sentimento de frustração causado pela ausência de uma parceria voltada para o desenvolvimento de um projeto socioeducacional voltado a atender o alunado que mora na UC. A proposta do modular para o ensino fundamental parece apontar para rumos novos, evitando que muitas crianças deixem, prematuramente, a companhia dos pais ao se deslocarem para outras localidades ou centro urbano para continuarem seus estudos. Isso que, ainda, a proposta curricular não tenha sofrido alterações no sentido de adequar-se às exigências locais e às dinâmicas novas sofridas com a criação da RESEX.

$O$ fato de a pesquisa não ter uma abrangência maior reduziu seu potencial para perceber a implementação de políticas educacionais diferenciadas em outras RESEX Marinhas amazônicas. Esses são os desafios principais para pesquisas novas, com outras questões teóricas que possam vir a ser aprofundadas para melhor revelar propostas educacionais viabilizadas a partir da realidade local com pretensões sustentáveis na Amazônia. Aliás, isso vem sendo proposto há tempos, mas o Estado não tem tido interesse e/ou capacidade quanto a sua efetivação.

\section{Referências}

Abélès, M.; Badaró, M. Obsesiones Antropológicas - Estado y resistencia. In: Abélès, M.; Badaró, M. Los encantos del poder: desafíos de la antropología política. 1. ed. Buenos Aires: Siglo XXI, 2015. p. 53-78.

Acevedo Marin, R.; Castro, E. R. Mobilização política de comunidades negras rural: domínios de um conhecimento praxiológico. Novos Cadernos NAEA, 2(2), 73-106, 1999.

Adorno, T. W. Educação e emancipação. 2. ed. São Paulo: Paz e Terra, 2000.

Allegretti, M. Políticas para o uso dos recursos naturais renováveis. In: Sachs, I.; Clusener-Goldt, M. (Org.). Extrativismo na Amazônia brasileira: perspectivas sobre o desenvolvimento regional. Paris: compêndio MAB 18 UNESCO, 1994. p. 14-31.

Allegretti, M. A construção institucional da Reserva Extrativista. In: A construção social de políticas ambientais: Chico Mendes e o movimento dos seringueiros. Brasília, DF: CDS; UnB, 2002. p. 462-588.

Alves, T. S.; Ubiratan C. G. Educar para as águas: experiências formativas nos territórios pesqueiros. II Simpósio Baiano de Geografia Agrária: entre a teoria e a prática, articulações e resistências. Salvador - Bahia Jul. de 2017. Disponível em: $<$ https://2sbga2017.ufba.br/sites/2sbga2017. ufba.br/files/eixo4_taise_claudio.pdf $>$. Acesso em: 03 out. 2017.

Aragón Vaca, L. E. Amazônia, crescer para desenvolver e conservar: cinco temas para um debate. São Paulo: HUCITEC, 2013. 
Aron, R. As etapas do pensamento sociológico. $4^{\mathrm{o}} \mathrm{ed}$. SP. Martins Fontes, 1993.

Azevedo, J. M. L. de. A educação como política pública. 2. ed. Campinas, SP: Autores Associados Editora, 2001.

Batista, I. M. da S.; Simonian, L. T. L. Implicações políticas, econômicas e socioambientais da RESEX Mãe Grande de Curuçá: perspectivas de desenvolvimento sustentável no estuário paraense? Belém, Novos Cadernos NAEA, 16(1), 203-220, 2013.

Bordenave, J. E. D. O que é participação. São Paulo: Brasiliense, 2007.

Brasil. Constituição da República Federativa do Brasil. Brasília: Senado Federal, 1988.

Brasil. Lei de Diretrizes e Base da Educação Nacional. Diário Oficial da União, Brasília, Seção 1, 23 de dezembro de 1996, p. 27833.

Brasil. Lei n. 9.985, de 18 de julho de 2000. Sistema Nacional de Unidades de Conservação-SNUC. Disponível em: $<$ http://www.mma.gov.br/port/sbf/dap/doc/ snuc.pdf $>$. Acesso em: 9 mar. 2010.

Costa, A. P. Educação e desenvolvimento: contrastes e perspectivas na Reserva Extrativista Verde para Sempre, Porto de Moz, Brasil. Pará, Dissertação (Mestrado em Planejamento do Desenvolvimento) - UFPA, Belém, 2009.

D'Incao, M. A. Limites culturais na responsabilidade de conservação da biodiversidade. In: D'Incao, M. A; Silveira, I. M. da (Org.). A Amazônia e a crise da modernização. Belém: Museu Paraense Emilio Goeldi, 1994. p. 25-35 (Coleção Galvão).

Ferreira, L. dos S. Políticas educacionais e desenvolvimento: a experiência da reserva extrativista marinha do Soure, Brasil. Pará, Dissertação (Mestrado em Planejamento do Desenvolvimento) - UFPA, Belém, 2002.

Gadotti, M. Educara para a sustentabilidade: uma contribuição à década da educação para o desenvolvimento sustentável. São Paulo. Livraria Instituto Paulo Freire, 2009.

Godoy, A. S. Pesquisa qualitativa: tipos fundamentais. Revista de Administração de Empresa, 35(3), 20-29, 1995.

Gohn, M. da G. Movimentos sociais e educação. São Paulo.
Cortez. 1999.

Gusmão, J. B. de. A construção da noção de qualidade da educação. Revista Ensaio: Avaliação e Políticas Públicas em Educação, 21(79), 299-322, 2013. Disponível em $<$ http://revistas.cesgranrio.org.br/index.php/ensaio/issue/ view/32>

Hamilton, D. The revival of learning? Educação \& Sociedade, 23(78), 187-198, 2002.

Höfling, E. de M. Estado e políticas (públicas) sociais. $\mathrm{Ca}$ derno Cedes, 21(55), 30-40, 2001.

IBGE - Instituto Brasileiro de Geografia e Estatística. Bases cartográficas. 2006. Disponivel em: $<$ http://www.siscom. ibge.gov.br/shapes/>. Acesso: em 10 de mar. 2014.

IDEB - Indice de Desenvolvimento da Educação Básica. VISEU: município do Pará. 2013. Disponível em: <http:// www.qedu.org.br/>. Acesso em: 11 out. 2014.

INEP - Instituto Nacional de Estudos e Pesquisas Anísio Teixeira. Censo escolar. 2013. Disponível em: < http://www. inep.gov.br/>. Acesso em: 10 jan. 2015.

Léna, P.; Oliveira, A. E. de. (Org.). Amazônia: a fronteira agrícola 20 anos depois. Belém, MPEG; ORSTOM, 1991.

Macedo, A. S. Políticas públicas educacionais em áreas de resex marinha: caso gurupi-piriá/ viseu-Pa. Brasil. Pará, Dissertação (Mestrado em Planejamento do Desenvolvimento) - UFPA, Belém, 2015.

Maciel, R. C. G. Ilhas de alta produtividade: inovação essencial para a manutenção dos seringueiros nas reservas extrativistas. Campinas, Brasil. São Paulo, Dissertação (Mestrado em Economia) - UEC, 2003.

Maciel, R. C. G. Projeto ASPF buscas alternativas de desenvolvimento Sustentável. Jornal Rio Branco, Rio branco, AC, 7 nov. 1999. Caderno 1, p. 2. Disponível em: <http// www.aspf.files.wordpress.com/2011/02/artigoprojetoaspf-claudiomaciel.pdf>. Acesso em: 27 fev. 2014.

Malinowski, B. Os argonautas do Pacifico ocidental. São Paulo: Abril Cultural, 1978.

Medina, N. M. (Coord.). Elementos para a introdução da dimensão ambiental na educação escolar $-1^{\circ}$. grau. In: Amazônia: uma proposta interdisciplinar de educação am- 
biental. Brasília DF: IBAMA, 1994.

Menezes, M. As reservas extrativistas como alternativas ao desenvolvimento na Amazônia. In: Arnt, R. (Org.). $O$ destino da floresta: reservas extrativistas e desenvolvimento sustentável na Amazônia. Rio de Janeiro: Relume-Dumará, 1994. p. 49-72.

Meletti, S. M. F.; Ribeiro, K. Indicadores educacionais sobre a educação especial no Brasil. Cadernos CEDES, 34(93), 175-189, 2014. doi: 10.1590/S0101-32622014000200003

MMA - Ministério do Meio Ambiente. Sistema compartilhado de informações ambientais. 2008. Disponivel em $<$ http://www.siscom.ibama.gov.br/shapes/>. Acesso: em 08 de mar. 2014.

Nascimento, E. P. Educação e desenvolvimento na contemporaneidade: dilema ou desafio? In: Bursztyn, M. (Org.). Ciência, ética e sustentabilidade: desafios ao novo século. Brasília: UNESCO, Cortez, UNB, 2001. p. 95-113.

Oliveira, R. C. de. O trabalho do antropólogo: olhar, ouvir, escrever. Revista de Antropologia, 39(1), 13-37, 1996.

ODM - Objetivos de Desenvolvimento do Milênio. Relatório nacional de acompanhamento. Brasília, DF: IPEA, 2010. Disponível em: <http://www. pnud. org.br/ Docs/4_Relatorio Nacional AcompanhamentoODM.pdf $>$. Acesso em: 15 dez. 2013.

Putnam, R. D. Comunidade e democracia: a experiência da Itália moderna. 3. ed. Rio de Janeiro: FGV, 2002.

Rea Rodriguez, C. R.; Ceballos Chavez, L. A.; Villasenor Palacios, B. A. Equilibrio sustentable y resistencia social en la cuenca del río San Pedro en Nayarit. Desacatos, México, 47, 116-131, 2015. Disponible en <http:// www.scielo. org. $\mathrm{mx} /$ scielo.php?script=sci_arttext\&pi$\mathrm{d}=\mathrm{S} 1607-050 \mathrm{X} 2015000100008 \& \operatorname{lng}=\mathrm{es} \& \mathrm{nrm}=\mathrm{iso}>$

Sauvé, L. Educação ambiental e desenvolvimento sustentável: uma análise complexa. Revista de Educação Pública, 6(10), 99-119, 1997.

Saviani, D. P. D. E. Plano de desenvolvimento da educação. Análise crítica da política do MEC. Campinas: Autores Associados, 2009.

Semed. Proposta de implantação do sistema modular para a Zona Rural. Prefeitura Municipal de Viseu- PA, Secretaria Municipal de Educação, Departamento de Ensino Fundamental, p. 1-25, dez. 2013.

Silva, J. B. Unidades de conservação e organizações de populações tradicionais sul-amapaenses: problemas, tendências e perspectivas, Belém, Brasil. Pará, Tese (Doutorado em Desenvolvimento Sustentável) - UFPA, 2007.

Silva, J. B.; Simonian, L. T. L.; Costa, A. P.; Batista, I. M. da S. Sustentabilidade institucional em Reservas Extrativistas na Amazônia brasileira. Papers do NAEA, 316, 3-20, 2013.

Silva, M. L.; Nascimento, A. L. C. Entrelaces de educação e meio ambiente por entre estradas amazônicas: o caso do programa de educação Ambiental para o asfaltamento da BR 230 (Transamazônica). Disponível em: <http//www. revesta.rcaap.pt/interaccoes/ article/viewFile/379/334>. Acesso em: 12 jan. 2015.

Simonian, L. T. L. Políticas públicas, desenvolvimento sustentável e recursos naturais em áreas de reserva na Amazônia brasileira. In: Coelho, M. C.; Simonian, L. T. L.; Fenzl, N. (Org.). Estado e políticas públicas na Amazônia: gestão de recursos naturais. Belém: CEJUP, UFPA; NAEA, 2000, p. 9-53.

Simonian, L. T. L. (Org.). Gestão de ilha de muitos recursos, histórias e habitantes: a experiência da Trambioca, Barcarena, PA. Belém: Editora do NAEA, 2004. 381 p., il.

Simonian, L. T. L. Pesquisa em ciências humanas e desenvolvimento entre as populações tradicionais amazônicas. Boletim do Museu Paraense Emílio Goeldi, 1(2), 119-134, 2005.

Simonian, L. T. L. Tendências recentes quanto à sustentabilidade no uso dos recursos naturais pelas populações tradicionais amazônidas. In: Aragón, E. (Org.). Populações e meio ambiente na pan-Amazônia. Belém: NAEA-UFPA, 2007, p. 25-44.

Souza, C. Políticas públicas: uma revisão da literatura. Sociologia, 8(16), 20-45, 2006.

Sousa, I. S. de. Aviamento e reciprocidade: estudo da vila de pescadores Apeú-Salvador - Viseu. Belém: 2000. 138 f. Dissertação (Mestrado em Antropologia) - Universidade Federal do Pará, 2000. 
Sterling, S. Sustainable education: revisioning learning and change. Bristol: Green Books, 2001.

Teixeira, E. C. O papel das politicas no desenvolvimento local e na transformação da realidade. Working paper, 2002. Disponível em: <http://www.fit.br/home/link/ texto/ politicas_publicas.pdf $>$. Acesso em: 10 fev. de 2014.

UNESCO - Organização das Nações Unidas para a Educação, a Ciência e a Cultura. Década das nações unidas de educação para o desenvolvimento sustentável, 2005-2014. Brasília, DF. 2005.
UNESCO - Organização das Nações Unidas para a Educação, a Ciência e a Cultura. Educação para os objetivos de desenvolvimento sustentável: agenda global da educação 2030. Brasil. 2017. Disponível em: $<$ http://unesdoc.unesco. org/images/0025/ 002521/252197POR.pdf.> Acesso em: 03 out. 2017.

Vergara Filho, W. L.; Silva, K. C. Laudo biológico dos manguezais do município de Viseu, Pará, Brasil. In: Processo 02018.001909/2001-19. Belém: MMA/IBAMA/CNPT, 2001. v. 1. 2001. p. 41-60. 